\title{
Chip-Based Microelectrodes for Detection of
}

\section{Single-Nucleotide Mismatch}

\author{
Xiaohong Li, ${ }^{a, b}$ Yinglin Zhou, ${ }^{a, b}$ Todd C. Sutherland, ${ }^{a, b}$ Brian Baker, ${ }^{c}$ Jeremy S. Lee, $*^{a}$ \\ Heinz-Bernhard Kraatz $*^{b}$
}

Supplemental Material

The microelectrode arrays were cleaned with MilliPore water and were characterized by cyclic voltammetry $(\mathrm{CV})$, electrochemical impedance spectroscopy (EIS), and atomic force microscopy (AFM). Figure S1 shows representative CV curves: a. bare microelectrode; $b$. coated microelectrode with ds-DNA. The CV results of the bare electrode show the redox reaction is a diffusive-controlled process. From the relationship between ip and $v^{1 / 2}$ as shown in Figure S2, the electrode area was evaluated to be $10.2( \pm$ 0.32) $\mu \mathrm{m}$. 


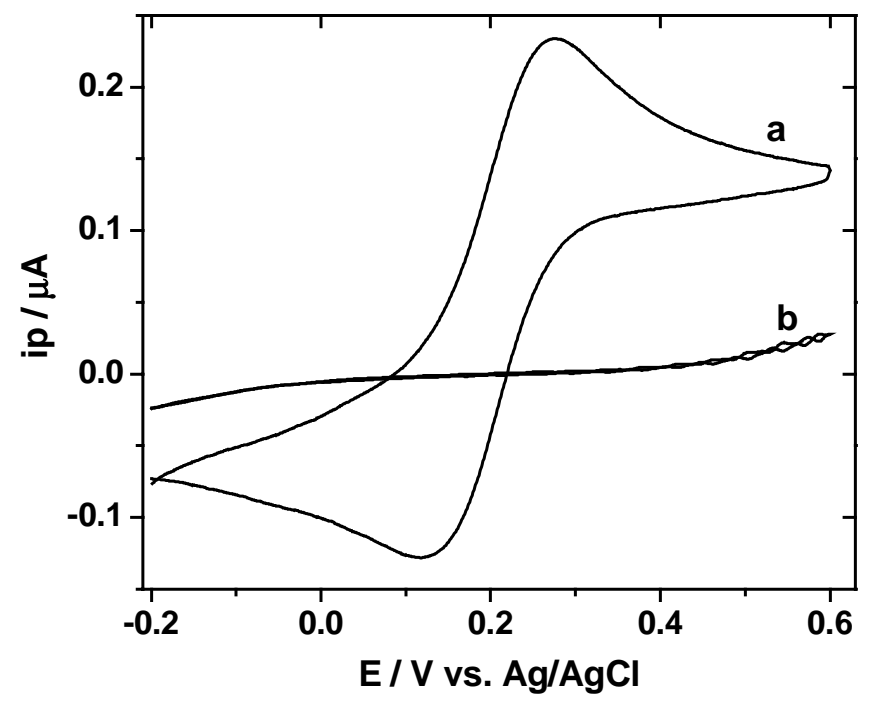

Figure S1. Representative CV curves for of one of the eight microelectrodes in $40 \mathrm{mM}$ $\mathrm{K}_{3}\left[\mathrm{Fe}(\mathrm{CN})_{6}\right]$ in $1 \mathrm{M} \mathrm{NaClO}_{4}$ solution: $\mathrm{a}$, on the bare electrode; $\mathrm{b}$. on the electrode coated with ds-DNA. Scan rate is $20 \mathrm{~V} / \mathrm{s}$.

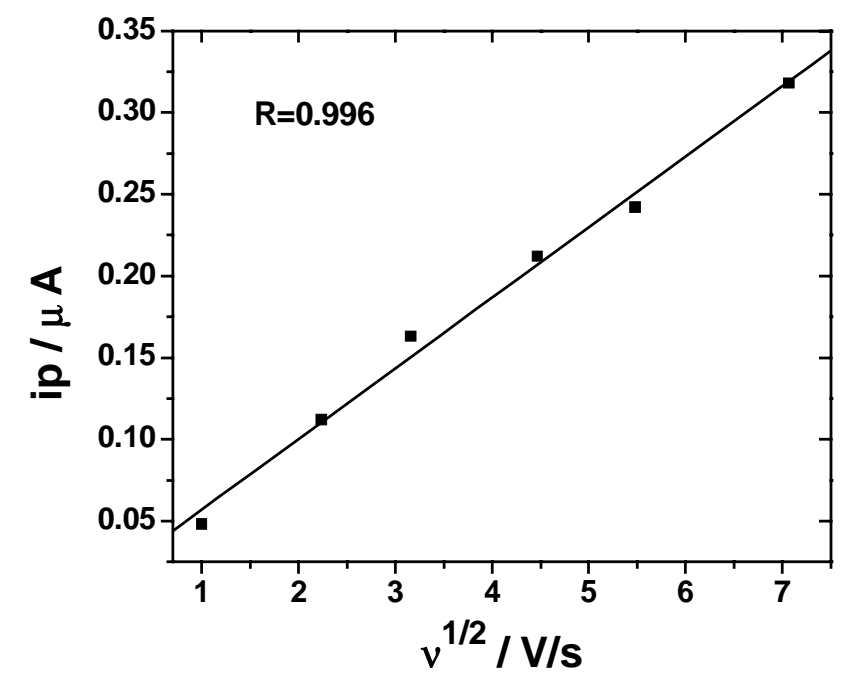

Figure S2. Diagram of the relationship between ip and $v^{1 / 2}$. This was used to evaluate the effective electrode area with the help of the Randles-Sevcic relationship. (see ref.) 


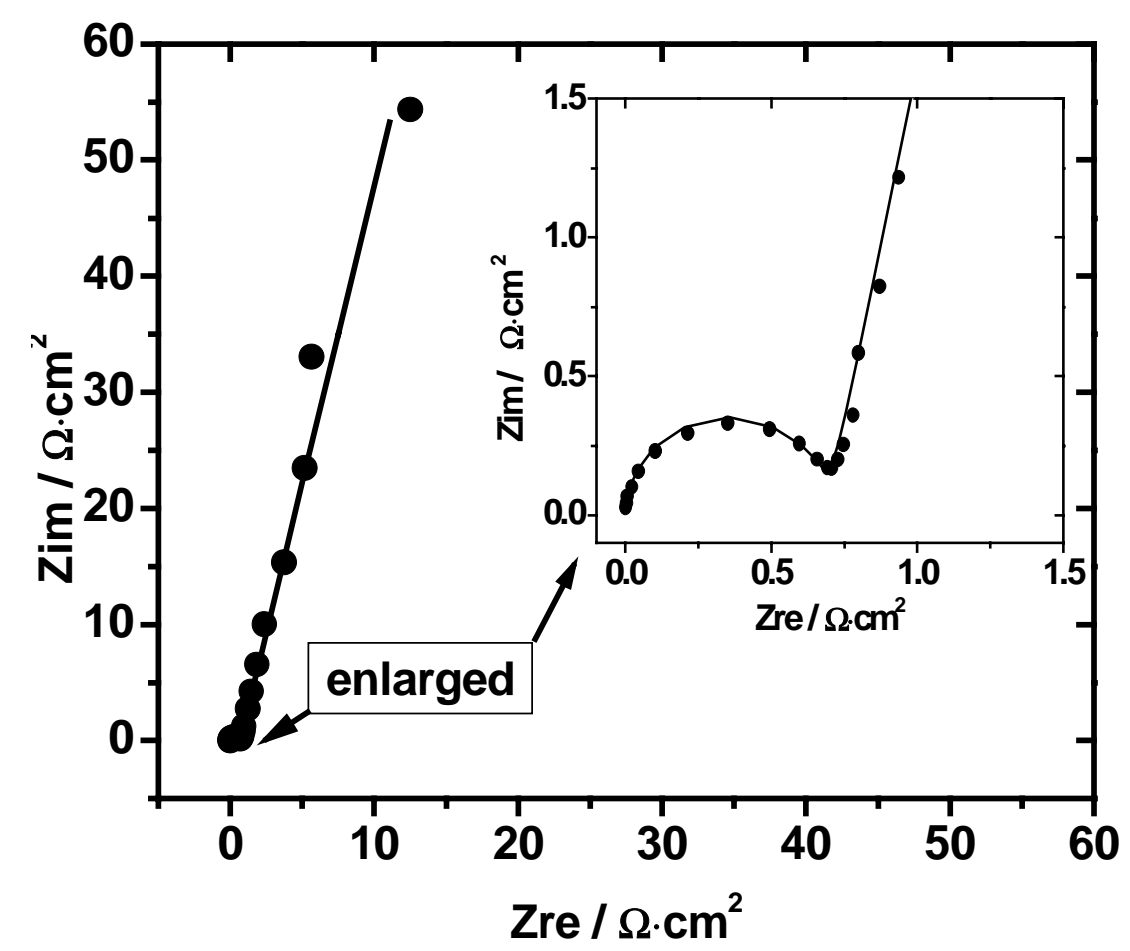

Figure S3 shows the results of an EIS study in the form of Nyquist plot $(4 \mathrm{mM}$ $\mathrm{K}_{3}\left[\mathrm{Fe}(\mathrm{CN})_{6}\right] / \mathrm{K}_{4}\left[\mathrm{Fe}(\mathrm{CN})_{6}\right](1: 1)$ in $50 \mathrm{mM}$ Tris- $\mathrm{ClO}_{4}$ solution, $\mathrm{pH}$ 8.7): measured data as symbols and fitting results as lines. It can be seen that a half circle appeared at higher frequency and a long diffusive tail at lower frequency. For bare microelectrodes, the mean diameter corresponding to the half circle is $0.7 \pm 0.07 \Omega \cdot \mathrm{cm}^{2}$, which means the charge transfer resistance $\left(\mathrm{R}_{\mathrm{CT}}\right)$ of redox probe on the bare electrode. 


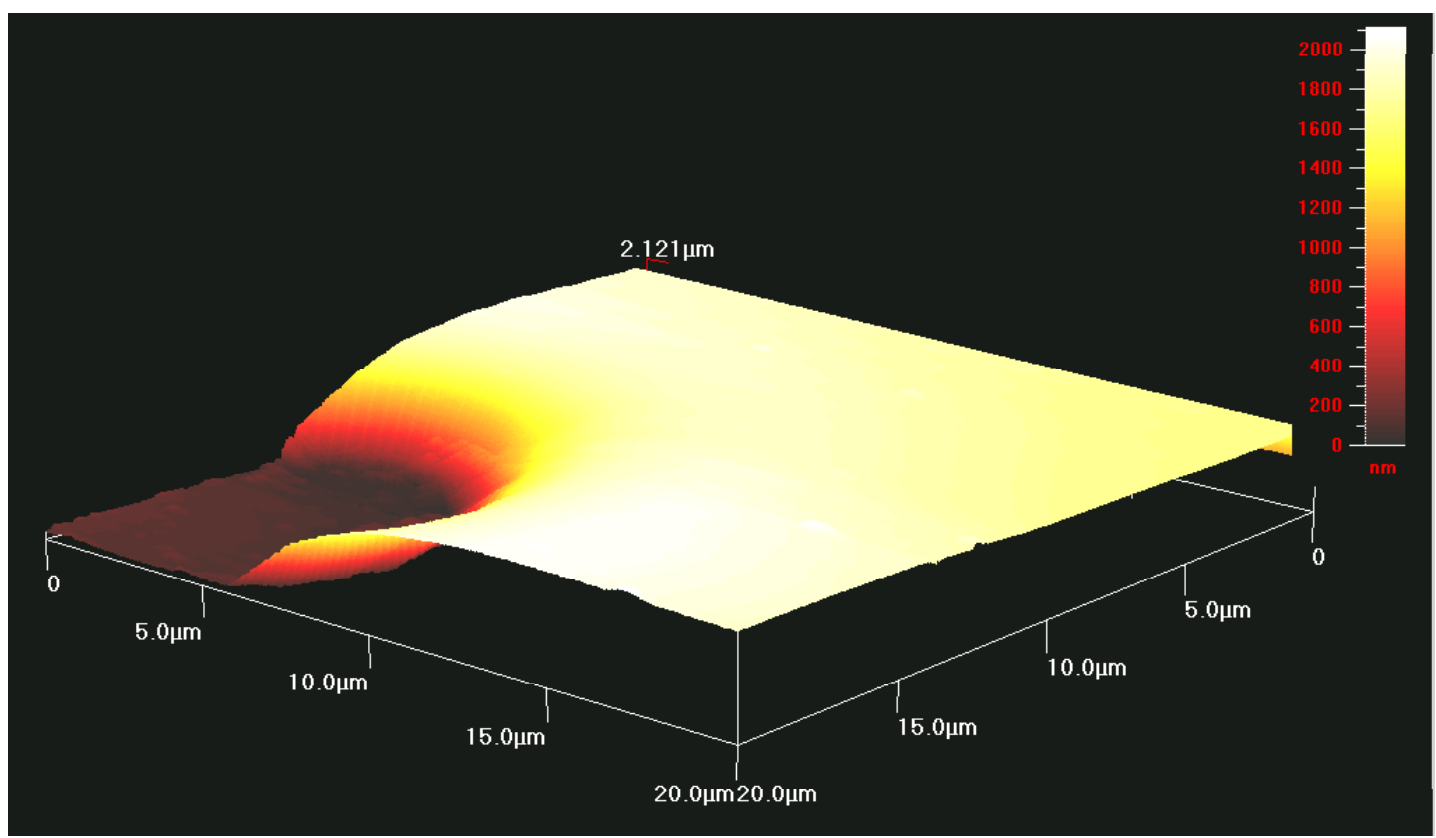

Figure S4 shows AFM image for part of the microelectrode

Figure S5: Three-electrode system used for the electrochemical measurements using a micro-positioning device (World Precision Instruments Model M3301R) to align the electrodes with the electrode array.

\section{$\mathrm{Ag} / \mathrm{AgCl}$ reference elelctrode}

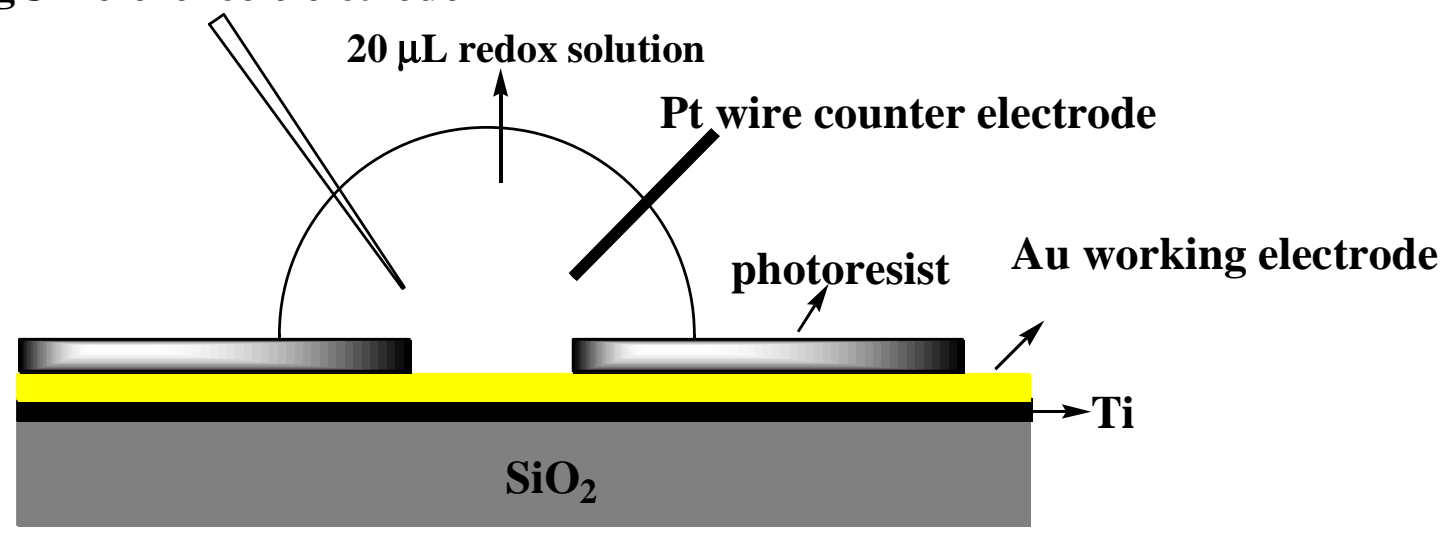


Ref:

J. Bard, L. R. Faulker, Electrochemical Methods. Fundamentals and Applications, $2^{\text {nd }}$ Ed., Ch. 6, Wiley, New York, 2001. 